\title{
Exploration and Practice of Graduation Design for Civil Engineering
}

\author{
MA Zhe ${ }^{\mathrm{a},{ }^{*}}, \mathrm{HAO} \mathrm{Xiao}^{\mathrm{a}}$ \\ ${ }^{a}$ Department of Civil and Materials Engineering, Henan University of Urban Construction, Pingdingshan,
} Henan, China

\begin{abstract}
Aimed at the present situation of the graduation design in Department of Civil and Materials Engineering, Henan University of Urban Construction, the author analyzed the problems in graduate design, focusing on the theme of improving teaching quality, training high quality professionals, from the design layout to adjust the time, conscientiously prepare for early mobilization, rationally choice the design topic to enhance the process of guiding, strengthening teaching stuff, improve the design evaluation system.
\end{abstract}

Index Terms: Practice; Civil Engineering; Graduation Design; Teaching Reform

(C) 2012 Published by MECS Publisher. Selection and/or peer review under responsibility of the International Conference on E-Business System and Education Technology

\section{Introduction}

Graduation design is an essential and important part of teaching procedures of civil engineering as well as developing students' ability of engineering practice, deepening and comprehensively applying professional knowledge in the teaching process [1]. Under the guidance of teachers, students comprehensively applying basic theories, professional knowledge and basic skills in practical training, which can not only improve the ability of analyzing and solving practical problems and engaging in scientific research, but also lay the foundation for entry into the engineering design, construction and management. It has not just a far-reaching influence on the students' moral character, work attitude, work style and ability to work independently with implications, but also on graduation and degree qualifications, and more important content for evaluation of education quality. How to improve the quality of graduation design and practical ability of students is an issue that we have been exploring in our teaching practice. The teaching reform for graduation design of Civil and Materials Engineering in recent years is as the following.

\section{The Problems in Graduation Design}

Department of Civil and Materials Engineering started to recruit students since 2002, and there are 5 groups of graduates. Throughout the 5-year graduation design, we have achieved good results students for the joint

* Corresponding author:

| E-mail address: ${ }^{*}$ mzmk@ @ncj.edu.cn 
efforts of all teachers and students, especially in recent years we further strengthen the management of graduation, so that the overall quality of graduation design has been improved significantly[2]. However, in the new situations of continued enrollment at the university and the difficulties of student employment, there were also some new problems need to be carefully studied and resolved in the graduation design. The main problems are as the following: Firstly, the graduation design is too single, students work in terms of task book, instructions and pre-design of specific dimensions given under the program design that teachers provided, which is not good for improving the students' innovation ability; Secondly, under the situations of continued enrollment and self-employment, the difficulty of employment increased sharply, some students take out a lot of time to contact work units, which left less time for graduation design; Thirdly, some students do not place enough emphasis on the graduation design as well as time and energy in the graduation, leading to the poor quality in design drawings, calculations, defense and oral defense; Fourthly, due to the increasing number of students, student-teacher ratio expanded, and the counseling left to instructors less time; Fifthly, the limited number of computers and they are older, software updates not timely, to a certain extent, affected the quality of graduation design; And finally, some of the instructors have not done engineering design.

\section{Deepening Reform, Strengthening Management of the Whole Process of Graduation Design}

In order to achieve the training objectives of training program requirements, based on the mature experience from other colleges and universities, combined with the characteristics of subjects, subject and the rules and regulations of department, we further improve the standardized management for graduation design, strengthen the further study of instructors, and closely around the topic, design reports, design guidelines, medium-term examination, evaluation for oral defense, sum up and other aspects of the reform and practice.

\subsection{Scientifically choosing design topic with combine of practice}

There should be depth and breadth for a graduation design topic, so that the basic and professional knowledge can be comprehensively applied for the graduate students in the design process. The instructors are required to collect design topics from multi-channel which are close to production, scientific research, technology development, process closely, as far as possible reflect the level of development expertise and cutting-edge developments[3]. Through the practice of the 4-year graduates since 2007, the graduate design topics of civil engineering turn from the direction of engineering design to research type. The engineering design can be derived from the institute of design, production projects, but also the plan from instructors, and the type of structure including the structure of modern popular form, and the proportion of masonry structure design subject declines. The design topics in line with the general trend of the development of building structure come from the scientific research projects of instructors. To stimulate students' interest in design, we adopted a "give out design topic, two-way selection, integrated control" approach, the students can choose them according to their own conditions and interest freely, and finally integrated control is taken by the Steering Committee based on the actual situation. Under the conditions of Increase in the number of students, ratio of student-teacher to be expanded, a given design plans in advance is difficult to ensure that one topic for person. A given design plans in advance was changed based on designs by students to complete their design requirements for that reason, the students must develop independent thinking from the work of program comparison to the analysis of construction feasibility, the actual economic indicators for assessment, but also understand the types of work-related coordination, so that we can realize the purpose of one topic for one person under the conditions of different conception and idea of the program. The abilities of the students in dealing with practical engineering can be trained through the process of design practice. 


\subsection{Set-up in advance and implement the reporting system of program}

Graduation design is usually arranged in the last semester before, many years of graduation design practice shows that the graduate students often feel helpless at the beginning of the design, unable to start, they need to take some time to become familiar with their design task[4]. Since many students need to be busy going to job interviews and other activities taking up some of their time, so that the already more limited design time cannot be guaranteed, affecting the quality of graduation design. Now the task of design is arranged in December every year, a mobilization meeting is held for the graduates to meet the instructors; the design topics, grouping, design schedule requirements, and the respondent timing are announced publicly. This will allow students to use vacation time to seriously consider the task of designing and requirements. They have enough time to collect data, make the design work in advance so that they can be engaged in enter the learning state in the last semester. the first two weeks of the eighth semester are the design phase, the first 3 to 4 weeks for graduation design practice, requiring the students to deepen their understanding of the design, having the building structural engineering which has been built corresponded with their own design project. In the first 4 weeks, after completion of the preliminary design, they should report to their instructors, students are required to took turns to report their initial designs, and the instructors comment on the preliminary design plans and organize the design team of students to discuss their proposed revisions. We control the copying phenomenon and create the conditions for setting the design. plans as soon as possible through this effective measures.

\subsection{Strengthening the management of all stages}

Strengthening the management of all stages is to improve quality assurance. Our approach is that the instructors make the overall schedule for graduation design based on the difficulty level of the design in order to control the design quality for different phases. As for the implementation of counseling time and responsibility, the instructors are required to have a regular inspection and supervision on the design, answering questions at any time, counseling at least twice a week for each instructor, but also asked to fill out the "Graduation Project Record Book", carefully prepare for guidance records. The mid-term review is also the focus of strict control for the design by the Department, each student should be required to fill out the mid-term graduation checklist, including the progress of work, the main work that has been completed, the work required to be done, problems and difficulties, and the instructors should make medium-term assessment on the students' work attitude, progress, quality, etc. The graduation designs can be included in the file after the approval of Department. As for the problem that the graduation design time for students is difficult to ensure, we developed detailed appraisal system at all stages, if the design cannot be completed in time will get deduction of point. Checking-in will be involved in all stages and the examination results will be taken as important reference for total grades of graduation design, which will not only supervise the students to complete the corresponding task in time, but also better control the graduation progress..

\subsection{Updating equipment and purchasing design software to enhance the further study of the instructors}

New computers and software such as Tianzheng Architecture, Tianzheng structure and PKPM have been bought in order to meet the graduation design requirements. In 2006 we held 2 training courses for instructors, designed by the experienced teachers and staff from our department and the design institute to give lectures on general layout design, process design, architectural design, structural design and related design technology, as well as the applications of main design software, including Tianzheng Architecture, Tianzheng structure, PKPM, TBSA, STRAT and the national standard construction requirements for the purpose of improving the instructors' ability. 


\subsection{Strict control of qualification for graduate reply}

After completion of graduate design, the students must first have self-revision for their own design documents, then do it between the students, and then marked by instructors for review. Written comments should be done by the instructors after they have done comprehensive review of the students' work ability and attitude, the level of graduation design and completion of design, after which the graduation design will be delivered to the teachers for qualification of graduate reply. Comprehensive review will be made by teachers on whether the workload of graduation design meets the requirements of teaching syllabus, whether the technical measures of design, calculation parameters, the choice of technical and economic indicators are reasonable, as well as description of the motion and writing quality, quantity and quality of drawing a in order to determine the qualification for graduate reply. After three trials, according to review comments the revised design documents can be taken as the final outcome of graduation design to participate in the graduate reply. The students are required to hand in not less than three hand-painted drawings to enhance the ability of each student; the others can be drawn by computer. To standardize graduation design, all design drawings are required using No.1 design paper.

\subsection{Graduation reply and achievements assessment}

Two levels of graduation reply -- team defense and department level defense are adopted. Team defense is done within the design team, the instructors and the students work together to present different opinions on the design of each student, so that each student can understand their own strengths and weaknesses of the design, the instructors make an objective evaluation on class performance of each student, which covers $60 \%$ of the total score. Department level defense take the mode of public defense in sub-groups. The Thesis Supervisory Committee consists of the instructors, professional teachers and experts from specialized design institutes, each student is required to participate in public defense in group. The committee members scrutinize each student's graduate design, calculations, and prepare for the defense.

Each defense team have to appoint a recorder. The students will be given a10 minutes to state briefly the summary their main design, methods, and innovation ideas; and The Thesis Supervisory Committee will be given 5 minutes to examine the design drawings and correct irregularities in the graph in red, and the students will given 10 minutes to answer questions from the Thesis Supervisory Committee members. The questions comes from the student's design drawings and calculations book, usually $3 \sim 4$ questions. Students report on the defense process, questions by the respondent group members, etc. will be written in detail and the forms of graduation reply records will be filled out, which covers $40 \%$ of the total score. The proportion of excellent results covers $15 \%$, low achievers $10 \%$. The two levels of defense are in public.

The final grade of graduation design includes the scores from the instructors and the respondent Commission, the independent evaluation. The scores from the instructors includes the ability to document retrieval and review, design plan, workload, learning attitude, regulatory requirements, application, basic theory and professional knowledge, level of education. According to defense case, the scores from the Commission includes topics, the level of graduation design, workload, preparation for the defense, expression of graduation design and answering questions etc.. The percentile evaluation is used, the final results are calculated in accordance with the $60 \%, 40 \%$ respectively.

\section{Conclusion}

After reform and improvement of several graduation sessions of guidance, the positive aspects of exploration and practice are made from the following aspects: setting up graduation design in advance, pre-mobilization, rational choice of a design, enhancing the process of guiding, strengthening teaching staff, 
improvement of evaluation system, etc.. and the graduation design quality has improved remarkably, such as the graduation design results exhibition of 280 graduates from Civil Engineering, $90 \%$ of students complete the design drawings over 17, calculations and other instructions up to 100 pages or more. We also feel that only the continuous reform and development of contents and methods of the graduation design in the new situation can we enhance the training of the students' ability to analyze and solve the problems, and creative ability as well. Establishing and improving the quality monitoring system for the graduation design is designed to improve the quality of graduates and an effective way to train highly qualified professionals.

\section{References}

[1] Li Wei, Wang Xiaochu. Design of civil engineening graduate teching and practice of innovatioon[J].Journal of Shenyang Institute of Education,2009.11(2)63-65（in Chinese）

[2] Lu Peng et al. Guide the design phases of civil engineering graduate of [J]. TECHNOLOGY (academic research), 2008, (21): 333 . (in Chinese)

[3] Dai Sujuan, et al. Designed to improve the quality of Graduation Suggestions [J]. China Power Education, 2009, 13 (5) :134-135. (in Chinese)

[4] Wu Yun. Graduation Design Teaching and improve the countermeasures [J]. Northwest University for Nationalities (Natural Science), 2007, 28 (68) :85-88. (in Chinese) 